\title{
Language abilities of children with refugee back- grounds: Insights from case studies
}

\author{
Andrea A. N. MacLeod \\ University of Alberta \\ Rabia Sabah Meziane \\ Université de Montréal \\ Diane Pesco \\ Concordia University
}

\begin{abstract}
Since 2015, over 58,000 Syrian refugees have settled in Canada and, at the time of the 2016 national census, over a fifth had settled in the province of Quebec (Houle, 2019). The rising numbers of refugees and the risks associated with families' forced displacement have underscored the need to better understand and support the language of refugee children. The paper reports on the oral language of three Syrian children ages five and six years, drawing on data from parent interviews, teacher reports, measures of the children's language, and observations of their language use in a dual-language stimulation group, StimuLER. By triangulating this data, we were able to develop a rich and realistic portrait of each child's language abilities. For these three boys, we observed that the home language was vulnerable to delays and weaknesses, and that learning the language of school was a drawn-out process. We also documented that parents and teachers had difficulties communicating with one another, and thus had difficulty meeting the educational needs of these children. We conclude that to foster resiliency in these children who are refugees, schools must find a way to build bridges with the parents to support the children's language learning in both the language of school and at home.
\end{abstract}

Civil war in Syria has led millions to flee the country, including over 2.5 million children (Unicef Canada, 2019). Among the many consequences of civil war and subsequent migration are the disruptions to family life and the interruption of schooling (United Nations Security Council, 2015), both of which raise concern about the educational and developmental outcomes of children with refugee backgrounds. Yet, these outcomes continue to be understudied (Graham, Minhas, \& Paxton, 2016; Sullivan \& Simonson, 2016). Moreover, in their systematic review of research on educational outcomes and learning problems among youth who are refugees, Graham and colleagues (2016) found that only four of 34 studies reported on participants under the age of six years. These four studies of young children focused on cognitive and academic outcomes.

In the present study, we add to the scant literature on the language development of young children with refugee backgrounds by providing a multiple case study of three young Syrian children who had recently arrived to Canada and were participating in a language stimulation program as they transitioned to school. Duff and Anderson (2015) maintain that case studies allow researchers to not only examine language learning but to elucidate the environmental factors (e.g., social, cultural, and familial) that might be affecting such learning. Case study research can also readily accommodate participants' perspectives (or in the case of young children, parents' perspectives) on the language learning experience. Furthermore, in keeping with other types of qualitative research, researchers conducting case studies typically get to know the participant(s) and this knowledge can translate to a deeper and empathic understanding of their experiences and circumstances by the researcher, and ultimately, by her or his readers (Duff \& Anderson, 2015). All these features of case-study research make it particularly suitable for understanding language acquisition in populations that are understudied (Duff, 2014). Multiple case studies have the added benefit of revealing differences and similarities between cases that can help drive theory and future research (Duff \& Anderson, 2015).

A multiple case-study approach was well suited to our central aim: to develop profiles of the children, particularly the strengths and weaknesses of their language, by drawing on diverse sources of information. The sources included standardized language measures, observations of the 
children in naturalistic contexts, and parent and teacher reports concerning the children's language development and current language exposure. We also report parent, teacher, and researcher perspectives on the familial and school contexts for language learning. As the following paragraphs on the role of language in children's lives highlight, these contexts are influential in language outcomes.

\section{Language in the Lives of Children with Refugee Back- grounds}

To ensure optimal development, it is important that children are able to interact with individuals across different settings. An essential component of these interactions is language proficiency - in the languages used at home, in the community, and at school. As concluded by Walsh, Este, Krieg, and Giurgiu (2011) based on their study of a Roma community with refugee backgrounds living in Canada: "Language profoundly hinders nearly all interactions in a new country, not just contacts with institutional structures" (p. 609). Amongst children with refugee backgrounds, there is some evidence that an early age of arrival to the host country favours adaptation; Wilkinson (2002), for example, observed more positive educational outcomes for children who arrived at a younger age. However, experiences in the family and school contexts prior to and following immigration place young children who are refugees at risk for disrupted language development.

For children in multilingual contexts, proficiency in the languages of home and school can contribute to greater resiliency, defined by Ungar (2008) as the process of navigating and negotiating resources, rather than as a set of fixed outcomes. Resilient individuals make use of resources that are best adapted to their present concerns. For example, religion and community served as sources of strength for members of a Somali Bantu community with refugee backgrounds living in the United States (Betancourt et al., 2015). Proficiency in the community's language(s) presumably helps children access such strengths. From this perspective, language proficiency is not simply a boon, but a key factor in positive adaptation and resilient development.

\section{The Family Context}

To understand language development and proficiency amongst children from refugee backgrounds, it is important to consider the family context. The pre-migration experience within this context may impact children's early language development. Prior to immigrating, children may experience disruption of attachment due to either the absence of, or the separation from, primary caregivers (Kaplan, Stolk, Valibhoy, Tucker, \& Baker, 2016). Disrupted attachment, in turn, could deprive children of the rich interchanges that are essential to children's communication development (Topping, Dekhinet, \& Zeedyk, 2013; van Ijzendoorn, Dijkstra,

\footnotetext{
${ }^{1}$ Throughout this paper, we use the term "multilingual" to describe exposure to more than one language (e.g., French, English, and Arabic). The term thus encompasses bilingual exposure.
}

\& Bus, 1995). Children may also experience trauma during the pre-migratory period, including witnessing harm to family or community members (Kaplan et al., 2016).

Post-migration, the parent-child relationship may also be difficult due to economic hardship and difficulties experienced by parents in learning the new language and culture (Betancourt et al., 2015; Kanu, 2008; Riggs et al., 2012). Indeed, many parents who were refugees report difficulty in learning the language of the host community (Betancourt et al., 2015; Walsh et al., 2011). Thus, children's proficiency in the home language is essential for communication between parents and children. Additionally, it is important to recognize that for some families, proficiency in the host country language can be a double-edged sword. For example, in a Canadian-Roma community with refugee backgrounds, parents reported that their children's low proficiency in English posed a challenge to developing friendships at school but viewed higher proficiency as leading to a loss of fluency in the home language (Walsh et al., 2011). Moreover, although the children from the Roma community tended to adjust more quickly to the new culture than their parents, their greater proficiency in English thrust them into new roles by acting as translators for their parents (Walsh et al., 2011). There is evidence that support for the home language can help children succeed at school and ease acculturation, as well as promote children's sense of belonging in their families and connection to their country of birth (Portes \& Rumbaut, 2001). Research has shown that that children from multilingual $^{1}$ backgrounds who are able to communicate in the languages of home and school benefit from higher selfesteem and a stronger sense of identity than their peers who have limited proficiency in their home language (Portes \& Rumbault, 2001; Wong Filmore, 2000).

\section{The School Context}

Children's pre-migratory and post-migratory experiences with schooling also impact their language proficiency. For many refugees, education prior to migration was disrupted - either for the child or for the young parents. In the Syrian context, a high percentage of children attended school prior to the civil war, but attacks on schools quickly made attending school difficult (Sirin \& Rogers-Sirin, 2015). For those who fled the war, schooling often continues to be tenuous. For example, schooling in Turkish refugee camps has been limited due to the large size of the camps, limited material resources, and limitations on who can take on the role of teacher (Sirin \& Rogers-Sirin, 2015).

Once settled in the host country, children must acquire the school language, as not doing so prevents a child from understanding what is taught, asking questions, and interacting socially with peers, and can thus have negative repercussions on achievement and well-being (McBrien, 2005; Shakya et al., 2012). In refugee contexts, parent support for 
education post-migration has also been identified as a protective factor (Graham et al., 2016), although parents express difficulties in being actively involved in their child's education due to language barriers, cultural differences, and a lack of understanding of the expectations of the new school setting (Graham et al., 2016; Walsh et al., 2011). In addition, low proficiency in the language of schools is also taxing. For example, in the aforementioned study of a Somali Bantu community in the US, poor English-language skills were identified by both youth and caregivers as contributing to acculturation stress (Betancourt et al., 2015). A recent study of more than 2000 low-income children of preschool age showed that children who were first- or second-generation Americans lagged behind their peers with regards to language abilities (DeFeyter \& Winsler, 2009). Together, the research suggests that preschool-aged refugee children may have weaker language abilities than host country peers, similar to other immigrants, and that these may be further impacted by the refugee resettlement experience. For young Syrian refugees, the quick escalation of the war, the largescale displacement of the population, and the extended migration paths for families are significant risk factors for optimal language development.

\section{The support of language development}

Notwithstanding the challenges experienced by families, the resettlement experience and well-being of children with refugee backgrounds can be supported by school or community programs that are both culturally-responsive and evidence-based (Graham et al., 2016; Shakya et al., 2012; United Nations High Commissioner for Refugees, 2000). Moreover, timely intervention can help counter the trauma experienced by children prior to migration and its negative effects on their learning capacity (McBrien, 2005; Sinclair, 2001) and confidence in people in positions of authority, including teachers (Strekalova \& Hoot, 2008).

With such findings in mind, in 2016 our team began developing StimuLER: a program intended to support dual language development in young children with refugee backgrounds and thus enhance their participation at home, in their community, and at school (MacLeod, Meziane \& Pesco, In Press). In addition to dual language support, StimuLER integrates two strategies that research has shown to be beneficial for monolingual and dual language learning by young children: theme-based language stimulation (Bunce, 2008) and dialogic reading (Huennekens \& Xu, 2016; Tsybina \& EriksBrophy, 2010). The thematic approach has sufficiently varied themes to allow adults to respond flexibly to both the linguistic and emotional needs of children with refugee backgrounds. For example, we addressed themes such as "feelings", "food", and "family" that could potentially give children opportunities to talk not only about their current experiences at home and school, but also about their pre-migration and migration experiences. These themes also provide opportunities for children to build linguistic and conceptual bridges between their lives at home and school. We incorporated the reading of stories related to the session's theme and employed dialogic reading. Dialogic reading shares features with other "shared book reading" approaches (Trivette \& Dunst, 2007), but employs a unique set of techniques to increase the child's participation in storytelling and allow for adult scaffolding of the child's language. Researchers of dialogic reading further recommend that adults tailor their prompts to children's language abilities (Zevenbergen \& Whitehurst, 2003), such as asking more literal questions "what", "where", and "when" questions or more inferential and connecting questions to children. While the StimuLER program is not the focus of the present study, this brief description is relevant since participants were attending the program and observed in this context.

\section{The Present Study}

The present study focused on three Syrian children who had recently arrived to Canada as refugees, specifically to the province of Québec. Since 2015, over 58,000 Syrian refugees have arrived to Canada (Houle, 2019). At the time of the 2016 national census, a fifth of the total number had settled in Québec (Houle, 2016), and our communities continue to welcome new arrivals. French is the official and majority language of Québec, used across all public services including education, health, and social assistance, but a minority language within the Canadian context. Since 1977, the province has adopted laws to ensure the continued vitality of French. Amongst these is Bill 101, which states that children must be educated in French (limited exceptions must be approved individually by the Ministry of Education). School boards are divided by language (either French or English). The English schools typically offer some combination of English instruction, bilingual English-French instruction, and French immersion. For schools in the French-language school boards, educational services are dispensed in French (Québec, 2019: I-13.3, article 210), with the exception of second-language classes (e.g., English or Spanish classes). For many students, schooling is not in their mother tongue. This case is most pronounced in Montréal, the largest city in Québec, where over $43 \%$ of students in public schools have a language other than French or English as their mother tongue, although French and/or English may be used in the home (Comité de la gestion de la taxe scolaire de l'île de Montréal, 2018).

Our aim was to develop profiles of the children's language learning and language abilities by examining the familial and school contexts for language learning, the children's language development, and their current language exposure and abilities. We anticipated that the sum of information would be greater than its parts; specifically, we expected the profiles to be enriched by triangulating data from parent and teacher interviews, standardized language measures, and direct observations. We did not set out to differentiate language disorder from limited French proficiency. Given the paucity of knowledge about the language profiles of young children with refugee backgrounds, rich profiles are needed to inform practice and elucidate directions for further research. 


\section{Participants}

\section{Method}

Three boys from refugee backgrounds participated in the study: Addir, Bakir and Chahid (pseudonyms are used throughout the text). The boys' families came to Canada through the Canadian government sponsored program within the previous 12 months of participating in the present study. They ranged in age from $5 ; 10$ to $6 ; 6$ and were attending welcome classes at the kindergarten or grade 1 level. These classes, offered to children in Québec who begin school with no or very limited knowledge of French, are intended to support French learning and integration to the school setting through small class sizes and teachers with training in second language learning (Ministère de l'Éducation, du Loisir, et du Sport, 2014).

The study took place during the winter of the participants' first year of school in Canada. The children were attending our dual language stimulation program, offered in this instance to a group of seven children who had been referred to the program by their welcome class teacher. The criteria for participating in this group included attending a welcome class, speaking Arabic at home, and having French language abilities that were relatively weaker than other children in their class as reported by the teacher. Children who were refugees were prioritised for this group: the three participating boys and a fourth child met this key criterion but we were unable to establish contact with the fourth child's parents. None of the three participants were receiving other services related to language, cognitive, or learning delays or disorders, and none had been assessed for such services. Additional details about the program sessions are provided below in the section Observations of Functional Communication.

\section{Measures and Procedures}

To develop a language learning and language ability profile for each child, we assessed the child in each of their languages. This approach is in accord with recommendations for assessing the language of children exposed to more than one language, put forth in both the research literature (Bedore \& Peña, 2008; Gillam, Peña, \& Miller, 1999) and in clinical guidelines (American Speech and Hearing Association, n.d.; IDEA, 2004 cited in Caesar \& Kohler, 2007). In addition to direct assessments, we completed parent interviews, teacher interviews, and observations of language use, as described below.

Parent interviews. The parent interviews were conducted at the children's school by the first author. We obtained information about each child's language development, use, and exposure through parent questionnaires. The goal of the first instrument, the Canadian Questionnaire of Use and Exposure in Bilinguals (C-QUEB; MacLeod, unpublished) is to gather information regarding the family and child's language use and exposure. Questions are asked regarding the languages the child is exposed to and uses across different settings (i.e., home, community, school), by or with whom (i.e., parents, siblings, other adults), beginning at what age, and at what frequency (i.e., hourly estimates for a "typical" week). Based on this information, it is possible to estimate the percent of exposure to each language and the age at which exposure to additional language(s) began.

The Alberta Language and Development Questionnaire (ALDeQ; Paradis, Emmerzael, \& Duncan, 2010) was designed for gathering information about English language learners' (ELL) first language development. It is composed of four parts: early milestones, current first language abilities, behaviour patterns and activity preferences, and family history. Total scores on the ALDeQ have been found to distinguish typical language development from language impairment amongst English language learners (ELL). More specifically, in the norming sample, an ALDeQ score of .66 or lower (i.e., 1.25 standard deviations below the mean) was more consistent with the language profiles of children with language impairment than with the profiles of children with typical language development (Paradis et al., 2010). Although the ALDeQ's discriminative validity has not been tested for French language learners, and the scores must thus be interpreted with caution, it proved useful in gathering data for the three boys in our study.

Teacher interviews. Teachers were asked to briefly explain why they had recommended each child participate in the language stimulation program. We also asked questions about the child's ability to communicate orally and his reading and writing abilities when applicable.

Measures of children's language. To gather further information about the children's language, we administered receptive vocabulary measures in French and Arabic and a non-word repetition task. The participating children were assessed in a quiet space by trained graduate students, one who spoke French and the other, Arabic. The direct assessments were conducted on the same day. We also observed children during language stimulation sessions communicating in both of their languages.

The children's single-word receptive vocabulary was measured with adaptations of the Peabody Picture Vocabulary Test to French (i.e., Échelle de vocabulaire en images Peabody [EVIP]; Dunn, Thériault-Whalen, \& Dunn, 1993), and a similar task in Arabic (i.e., the Arabic Vocabulary Subtest, Al Janaideh, 2019). In accord with the test guidelines, the examiner read a word aloud and asked the child to point to the corresponding picture from a set of four pictures.

We administered a non-word repetition task as a measure of language processing. Such tasks have been shown to distinguish children with and without language impairment in monolingual (Gathercole, 2006) and bilingual children (Dollaghan \& Horner, 2011). For this task, the children were presented with a total of 40 non-words increasing in syllable length from two to five syllables and were asked to repeat each one (Courcy, 2000). The repetitions were scored for the number of phonemes correct (i.e., phonemes produced accurately or with minor distortions and in the correct position in the word). Omitted, dislocated, or substituted 
phonemes received a score of zero. This specific non-word repetition task has been used to assess French-speaking children between the ages of four and six years with typical and impaired language impairment (Thordardottir et al., 2011). The results suggest that scores on this task that are 1.28 standard deviations or more below the mean (i.e., scores of .82 or lower) are consistent with a profile of impaired language development (Thordardottir et al., 2011).

Observations of children's functional communication. Children's communication and ability to harness their language skills in a functional setting were observed in the language stimulation group setting. The StimuLER program provided support for children who were referred by their teachers for additional language stimulation. The language stimulation program was carried out at the children's school by two university-level students in French, assisted by a graduate student who spoke Arabic. These students had received training from our research team in dialogic reading and in animating small groups to stimulate oral language abilities. The students (referred to later in the paper as "animators") prepared the sessions ahead of time, and the weekly plans were reviewed by the first author. A total of seven children, all of whom spoke Arabic at home, participated in the sessions. The sessions were held in a quiet room once a week for 10 weeks. Each session lasted one hour with the following structure: a welcome song (French), dialogic reading (French and Arabic), an interactive activity (e.g., for the "food" theme, children selected pictures of fruits and vegetables to decorate a plate; French and Arabic), and a goodbye song (French). Opportunities to use each language were woven into each activity, with one animator speaking French and the other speaking mainly Arabic. In addition, children's responses in either language were welcomed. For responses in Arabic, the bilingual animator acknowledged the response, and provided a comment and translation for the benefit of the children, as well as the other animator.

The sessions from which the data in the present study was derived were organised around two themes: food (drawing on the French translation of Eric Carle's The Very Hungry Caterpillar), and emotions (using Orianne Lallemand and Eléonore Thuillier's Le loup qui apprivoisait ses émotions). For each theme, a subset of functional words and short phrases were targeted for emphasis during the intervention sessions. Questions were prepared in advance to solicit the participation of the children following the dialogic approach. We ensured that all children had the opportunity to participate by targeting each child for a question, encouraging responses, and supporting comments. This goal was aided by the presence of three adults; one adult led the reading activity while the two others provided support to the children.

During these two language stimulation sessions, we observed the children's communication during dialogic reading as this portion of the sessions unfolded in a similar manner each week and represents a common classroom activity. Using a grid designed for the study, the two animators noted the child's turn-taking; speaking role (initiator or respondent); number and type of communicative attempts (gestures, vocalizations, isolated words, word combinations, agrammatical sentences, grammatical sentences); and number and type of communication intentions (requests, answers, salutations, drawing attention, expressing emotions, initiating exchanges, imitation, making a comment, protests). The dialogical reading was audio recorded to avoid potential parental discomfort with video recording yet permit more detailed information than observations in real time allow. The audio recordings were transcribed and used to verify the observations made during the sessions.

\section{Results}

The goal of the present study was to develop profiles of the strengths and weaknesses of the language learning and language abilities of children from refugee backgrounds. We begin by presenting findings from the parent interviews, language measures, and observations of Addir, Bakir, and Chahid, in turn. These are followed by a section where we compare and contrast the individual results.

\section{Addir}

Parent interview. Addir was 6;2 at the beginning of the study and was attending a "welcome" kindergarten class. His family had arrived in Canada 10 months prior to the study. He lived with his mother and his older siblings, but his father has stayed in a middle-eastern country to continue working during this transition. His parents were professionals, his mother a lawyer and his father an engineer. His mother did not speak French. We met the mother at school to obtain her consent to participate in the study and to conduct the interview. She arrived with a few different memos that were sent home from school, one that described our research but others that were about different events at school. She expressed her frustration and difficulty making sense of the various documents from school, written in French. She noted that she uses Google Translate, and also asks her older children for help. For our interview, we spoke in English (a language the mother felt more comfortable with than French) and used Google Translate to translate questions and responses when she felt she did not understand the question or to clarify her response. Table 1 provides a summary of the results from the structured interview and language assessment.

The structured interview focused on a series of questions about Addir's language use and exposure (BLUEQ), and language development and language proficiency (ALDeQ). The interview revealed that Addir was exposed to Arabic at home and some English through television, videos on the internet, and books. The family used Arabic to communicate with one another. His exposure to French was recent and limited to the school context. Based on the questionnaire, Addir was exposed to Arabic close to $60 \%$ of his time and to French for $40 \%$ of his time. His current exposure to English was passive and limited to media, but he had been schooled for one year in Arabic and English prior to arriving 
in Canada.

Regarding her son's language abilities in Arabic, Addir's mother noted that he was quite delayed producing his first words (around 3 years of age) and continued to have difficulty producing longer sentences. She reported that she often provides Addir with a model, but he sometimes mumbles the first part and only correctly produces the final word. She also noted that his speech can be difficult to understand. In contrast, she found that he understands well but stated that she explains what to do several times to help him understand. In addition to Arabic, Addir's mother noted that he has learned some French and English words. He mixes languages within sentences (e.g., "Where's my chapeau?"), or use the word that is "the simplest" across the three languages (e.g., she notes that he says "rainbow" in English rather than the Arabic or French). She stated that her older son (10 years old) learned French well, but that French seems harder for Addir. In contrast, she found that he repeats and adds words in English more easily, through viewing YouTube.

As shown in Table 1, Addir's score on the ALDeQ was 0.25. Based on the ALDeQ guidelines, this score places him at risk for having a language impairment. The four subparts of the ALDeQ provide insight with regards to Addir's language abilities. Part A focuses on early developmental milestones, Addir had delays in producing his first words and sentences (ALDeQ-Part A: 3/18). Part B focuses on current abilities in the first language; these were reported to be weak and included difficulties producing longer sentences and pronunciation (ALDeQ-Part B: 3/18). Part C describes behaviour patterns and preferred activities, reported by Addir's mother to include drawing and looking at books. She also described Addir as needing time to learn new activities but able to stay somewhat focused on a task (ALDeQ-Part C: 9/15). Part D asks about the family history, including level of education and presence of language learning difficulties. Addir's mother reported that family members have completed high school but also the presence of a language-learning difficulty in the family (ALDeQ-Part D: 3/9).

Teacher interview. Addir attended school for one year prior to moving to Canada, and the language of schooling was Arabic and English. At the time of this study, he was six years old and attending a "welcome" kindergarten class and was thus enrolled at an appropriate grade for his age. Despite being among other children who are learning French as a second language at school, his teacher noted that he speaks very little in the class and appears to have difficulty understanding messages in the classroom setting. The teacher also noted that he has difficulty learning letters and has little phonological awareness. She claimed that he has little support for his learning at home since his parents do not speak French.

Language measures. To provide an overview of Addir's language abilities, we assessed his receptive vocabulary in French and in Arabic. He was unable to complete the training items of the vocabulary test in French and did not comprehend the task. He fared better in Arabic: he was able to point to a few images and obtained a score of 3 correct, but only completed 9 items before accumulating 6 errors in a block of 8 items (the discontinue rule for the test). His nonword repetition abilities were very weak; he obtained a score of .06 (or 17 correct phonemes out of 280). He spoke very quietly. On the two-syllable non-words, he produced a number of errors on consonants, but repeated the correct number of syllables and was quite accurate in his vowel production. He quickly began to struggle as the syllable length increased from three, to four. and then to five syllables. This assessment coincides with his mother's observations and concerns regarding his language development. He appears to have difficulty participating and understanding tasks in French, and to a somewhat lesser extent in Arabic. He shows considerable difficulty repeating non-words, suggesting weakness in language processing.

Functional communication. Addir was an active listener in the language stimulation group and paid attention to the story during the dialogic reading portion of the language stimulation sessions. However, he spoke very little, in either French or Arabic. He occasionally missed turns by not responding or waiting for the next child to speak. He gestured spontaneously, but produced isolated words only in imitation of the session animator or a peer. He spoke very softly. With regard to communication intentions, he only responded to questions or requests for imitations. The results from the observations of his participation in the group are provided in Table 2.

\section{Bakir}

Parent interview. Bakir was $5 ; 10$ at the beginning of the study. His family had arrived in Canada four months prior to the study. Like Addir, he lived with his mother and his younger sister, but his father has stayed in a middle-eastern country to work during the transition to Canada. His parents were both teachers, but his father presently worked as an electrician. His mother did not speak French. We met the mother at school to obtain her consent to participate in the study and to conduct the interview. We spoke in English and she was able to answer the questions and clearly indicated when she required further clarification. The results from the structured interview and language assessment are provided in Table 1.

As for the other participants, the BLUE-Q and ALDeQ questionnaires were used to structure the interview. These revealed that Bakir's language use and exposure was limited to Arabic at home (close to $60 \%$ of his time), and French at school for the remaining $40 \%$. He was exposed to both languages through books, television, and videos on the internet. His family used Arabic to communicate with one another.

When turning to her son's language abilities, Bakir's mother expressed concerns. She reported that he began producing his first words around the age of $2 ; 6$, and his first sentences about a year later. She noted that he does not express himself very well compared to other children and his speech can be a bit difficult to understand. He tends to speak 
in short sentences and has difficulties producing longer sentences. She reported that he is quite active at home, but that at school the teacher says that he is very quiet. She also noted that his teacher reports he avoids eye contact with others at school. She said that Bakir does this at home, but only when he wants to have "a serious conversation". He likes to listen to stories, and she wished she had more time to read to him. He loves to play video games, but she had recently limited the time spent on videogames to weekends only based on advice from a paediatrician. He likes to count in French and speaks a bit of French with his parents. His mother noted that he can be very tired at the end of a day of school and easily upset by changes to his routine.

Bakir's score on the ALDEQ was .416, which places him at risk for having a language impairment. His scores on each subtest are consistent with the low overall score. With regards to developmental milestones, Bakir was late in producing his first words and sentences (ALDeQ-Part A: 3/18). He continues to show difficulties in producing longer sentences and in pronunciation and needs time to produce longer sentences (ALDeQ-Part B: 5/18). His behaviour patterns and preferred activities include playing with blocks and video games, and he enjoys listening to stories. He needed time to learn new tasks (ALDeQ-Part C: 8/18). With regards to family history, Bakir's mother reported that family members have completed high school and that there was no family history of language learning problems (ALDeQ-Part D: 9/9).

Teacher interview. Bakir had not attended school until arriving in Canada and was integrated into a "welcome" kindergarten class. He was presently enrolled at an appropriate grade for his age. His teacher noted that he speaks very little in the class, interacts little with his peers, and generally seems to have little interest in communicating. The teacher claimed that there is little support for his schooling since parents do not speak French at home.

Language measures. Bakir's language abilities were assessed through the receptive vocabulary tasks in French and Arabic, and a non-word repetition task. He struggled to participate in these tasks but did appear to understand the instructions. He obtained a raw score of 7 on the French task and completed 22 items. He did not respond to the examiner on the Arabic task and we were unable to obtain a score. Finally, on the non-word repetition task, he spoke quietly and was able to repeat the two-syllable and three-syllable words quite well, but began to accumulate errors and refuse to repeat words beginning with the four-syllable words. He obtained a score of .264 (or 74 correct phonemes out of 280). This assessment coincides with his mother's observations and concerns regarding his language development. His difficulty in participating in tasks and in non-word repetition suggests weakness in language processing. He was also quite withdrawn in new situations, which may result in an underestimate of his overall abilities, especially in Arabic.

Functional communication. In the first sessions of the language stimulation group, Bakir was shy and did not make much eye contact. He did not respond to questions directed at the group, but did respond to questions directed at him, particularly with a model. He whispered his responses at first, and then began to voice his responses but still very quietly. He seemed a bit curious and surprised when session animators asked him to repeat or answer in Arabic, but he was willing to do so. He often did not take his turn when it was available, particularly at the beginning of the sessions. He produced a range of types of productions, but no sentences. His word combinations were in imitation of the animator. He produced limited types of communicative intentions, only direct answers or imitations. Generally, his language abilities seemed stronger than Addir's, but appeared hampered by his shyness. The results from the observations of his participation in the group are provided in Table 2.

\section{Chahid}

Parent interview. Chahid was $6 ; 6$ at the beginning of the study. His family had arrived in Canada 10 months prior to the study. He lived with his parents and his older siblings. His father had a bachelor's degree in English literature, and his mother was a baker. Although neither speak French, Chahid's mother quickly found work at a local baker, but his father has struggled to find work. We met with his father at school to obtain his consent to participate in the study and conduct the interview. The interview was conducted in English, as Chahid's father is fluent in the language. He spoke spontaneously about the challenges of moving to Québec and the school system. He noted that communication in French is difficult, and that learning a new language as an adult is slow. He stated that more needs to be done to help people during this transition. He noted that it is very time consuming to go through piles of papers that arrive from school and that one needs to decode each page as they are all written in French. He found that they had little support as newcomers within the school context and found it difficult to share what his children are learning. The results from the structured interview and language assessment are provided in Table 1.

The same questionnaires (i.e., BLUE-Q, ALDeQ) used for the other boys were again used in the structured interview. Chahid was exposed to Arabic at home and some English through television, videos on the internet, and books. His father noted that it is difficult to find interesting resources for French on the television or the internet. Based on the questionnaire, Chahid is exposed to Arabic close to $60 \%$ of his time, to French for $40 \%$, and passively to English via media.

Chahid's father noted that Chahid was late to walk, and to produce his first words and first sentences. He noted that Chahid continues to have difficulties "conjugating" words in Arabic and difficulty transitioning between sentences, and will invent words, declensions, and conjugations when he doesn't know how to say a word correctly. Chahid also does not contrast two consonants, /d/ vs. /ð/, although his father noted that this contrast is absent in the dialect of Arabic the family speaks, contrary to Standard Arabic. His father noted that Chahid cannot write or recognize letters in Arabic and that he was too young to begin school before they began their migration process. His father noted that he wants 
Chahid to become comfortable with reading in French and English before turning to Arabic. He noted that he is discouraged that his children are not very interested in books, and prefer to play video games and watch videos on the internet. He stated that Chahid is interested in playing with Legos and toy cars and develops scenarios in his play. He learns slowly and will often ask an adult to help him - a behaviour that his father blames on being "puppied" as the youngest member of the family. Chahid is motivated to learn more by his peers than to please adults around him, and his father observes him trying new things more when he is around other children. For instance, Chahid will sometimes use French when speaking with other children. His father noted that when Chahid hears a new word, he will ask what it means in Arabic, English and French. As an example of his son's ability to communicate even when he struggles to find words, he noted that if Chahid wanted to eat at a particular restaurant, he would act out how to prepare food or provide the streets to take to get to the place.

Chahid's score on the ALDEQ was .51, which also places him at risk for having a language impairment. With regard to early developmental milestones, he had delays in producing his first words but less so with first sentences (ALDeQ-Part A: 10/18). As for his current abilities in the first language, Chahid is reported to have some difficulty with declensions and conjugations in Arabic and difficulty in transitioning between sentences (ALDeQ-Part B: 9/18). His behaviour patterns and preferred activities included playing with Legos, creating stories with cars, and playing video games. His father reports that he needs time to learn, but tries new things more willingly when he is with other children (ALDeQ-Part C: 10/18). Finally, while members of Chahid's family have graduated from high school, two family members have had language learning difficulties (ALDeQ-Part D: 3/9). In particular, one member of the family had a slow onset of speech, a delay that Chahid's father attributed to emotional trauma due to the war in Syria.

Teacher interview. Chahid was attending a "welcome" Grade 1 class, and thus is enrolled at an appropriate grade for his age. His teacher stated that he needs to use French more often. She also suggested that his parents should be more involved in his learning and that they should provide more structure and support in completing his homework. She described his spoken, reading, and writing abilities as weak.

Language measures. We assessed Chahid's receptive vocabulary in French and Arabic, and his non-word repetition. The results from the language assessment are provided in Table 1. In French, he obtained a raw score of 22 and completed 40 items. He understood the task, listened carefully, and tried to identify the picture that went with the word. In Arabic, he obtained a score of 9 and 16 items were completed. In the non-word repetition task, he listened carefully and repeated accurately words of two, three, and four syllables but produced more errors in the longest non-words. He obtained a score of .79 (or 222 correct phonemes out of 280). The moderate difficulties observed in receptive vocab- ulary and language processing coincide with Chahid's father's observations and concerns regarding his language development.

Functional communication. Starting with the first session of the language stimulation group, Chahid was chatty and spontaneously provided answers in Arabic. He enjoyed providing translations in Arabic for each word encountered in French. He would also correct the non-Arabic-speaking assistant when she attempted to produce words in Arabic. When he didn't know how to answer in French, he said "je sais pas comment" (I don't know how). He was willing to provide answers in Arabic and then imitate following a model in French. He also helped Bakir to answer questions by speaking in Arabic with him. He infrequently missed a turn, but was sometimes off topic (e.g., speaking about his sore throat). He produced diverse types of communications, including all but vocalisations. He also produced a range of communicative intentions, with the exception of expressing emotions. The results from the observations of his participation in the group are provided in Table 2.

\section{Addir, Bakir, and Chahid: Similarities and Differences across Cases}

When viewed together, these three boys have a number of similarities and differences with regards to their language learning experiences, their abilities in Arabic and French, and their functional communication. We have summarized the information in Tables 1 and 2 below. The three boys have very similar profiles with respect to language exposure. Arabic was used in the home in all interactions and French was used exclusively in school. Despite continued exposure to Arabic since birth, and relatively recent introduction of French, the three children's parents report slow development of Arabic evident in the late emergence of first words and first sentences. The three children had low scores on the ALDeQ subsection A, and also low scores overall on this tool. When assessed directly, the children's responses on the receptive vocabulary task in Arabic were very low, and Bakir did not respond to the task. They also had very low scores on the French receptive vocabulary task, with Chahid obtaining a higher score than the two other boys. Interestingly, Chahid obtained a relatively robust score on the nonword repetition task compared to the two other boys, supporting the observation of stronger language abilities.

Table 1. Language Measures from Parent Report and Direct Assessment across Cases

\begin{tabular}{llcccc}
$\begin{array}{l}\text { Partic- } \\
\text { ipant }\end{array}$ & $\begin{array}{l}\text { Lan- } \\
\text { guage } \\
\text { Expo- } \\
\text { sure }\end{array}$ & ALDeQ & $\begin{array}{c}\text { Ara- } \\
\text { bic } \\
\text { Vo- } \\
\text { cab- } \\
\text { ulary }\end{array}$ & $\begin{array}{c}\text { French } \\
\text { Vocab- } \\
\text { ulary } \\
\text { (EVIP) }\end{array}$ & $\begin{array}{l}\text { Non- } \\
\text { word } \\
\text { Repe- } \\
\text { tition }\end{array}$ \\
\hline Addir & $\begin{array}{l}60 \% \\
\text { Arabic; } \\
40 \%\end{array}$ & .25 & 3 & 0 & .060 \\
& & & &
\end{tabular}




\begin{tabular}{|c|c|c|c|c|c|}
\hline & French & & & & \\
\hline Bakir & $\begin{array}{l}60 \% \\
\text { Arabic; } \\
40 \% \\
\text { French }\end{array}$ & .42 & 0 & 7 & .264 \\
\hline $\begin{array}{l}\text { Cha- } \\
\text { hid }\end{array}$ & $\begin{array}{l}60 \% \\
\text { Arabic; } \\
40 \% \\
\text { French }\end{array}$ & .51 & 9 & 22 & .793 \\
\hline
\end{tabular}

Our observations of the children's participation in dialogic reading activities contributed important data with regards to their ability to harness their language skills in a learning context. Three distinct profiles were observed and are summarized in Table 2. Although both Addir and Chahid took a number of turns, the quality of their communication forms and intentions were quite different. Addir produced mostly gestures and isolated words and his turns were limited to answering the assistant's questions and imitating upon request. In contrast, Chahid produced a range of communication types and intentions and spontaneously provided responses. Finally, Bakir was quite shy and responded infrequently but when he did, he used a range of communication types, with the exclusion of sentence-length responses. These observations provide rich information about the children's communication in an active setting.

Table 2. Observation of Functional Communication across Cases

\begin{tabular}{|c|c|c|c|}
\hline $\begin{array}{l}\text { Par- } \\
\text { tici- } \\
\text { pant }\end{array}$ & $\begin{array}{l}\text { Number of } \\
\text { Turns / } \\
\text { Total Elic- } \\
\text { ited }\end{array}$ & $\begin{array}{l}\text { Types of Com- } \\
\text { munication } \\
\text { Forms }\end{array}$ & $\begin{array}{l}\text { Types of Com- } \\
\text { munication In- } \\
\text { tentions }\end{array}$ \\
\hline Addir & $\begin{array}{l}10 / 13 \\
(77 \%)\end{array}$ & $\begin{array}{l}2 \text { of } 6 \text { (only } \\
\text { gestures and } \\
\text { isolated words) }\end{array}$ & $\begin{array}{l}2 \text { of } 9 \text { types } \\
\text { (only answer- } \\
\text { ing and imita- } \\
\text { tion) }\end{array}$ \\
\hline Bakir & $\begin{array}{l}7 / 15 \\
(46 \%)\end{array}$ & $\begin{array}{l}4 \text { of } 6 \text { (all but } \\
\text { sentences) }\end{array}$ & $\begin{array}{l}2 \text { of } 9 \text { types } \\
\text { (only answer- } \\
\text { ing and imita- } \\
\text { tion) }\end{array}$ \\
\hline $\begin{array}{l}\text { Cha- } \\
\text { hid }\end{array}$ & $7 / 8(87 \%)$ & $\begin{array}{l}5 \text { of } 6 \text { (all but } \\
\text { vocalisations) }\end{array}$ & $\begin{array}{l}8 \text { of } 9 \text { types } \\
\text { (all but ex- } \\
\text { pressing emo- } \\
\text { tions) }\end{array}$ \\
\hline
\end{tabular}

\section{Discussion}

In the present study we used a case study approach to develop profiles of the language learning and language abilities of children from refugee backgrounds. To this end, we focused on three young boys from Syria who had recently arrived in Canada. We developed the portraits of each child by triangulating data from parent interviews, teacher reports, standardized language measures, and direct observations of the children as they interacted with adults and peers. Based on these data and a cross-case analysis, we derived rich descriptions of the family and school contexts for language learning and of children's language exposure, language abilities, and language use.

\section{Familial Contexts}

Within the family context, we observed changes in the family responsibilities related to the migration, and challenges learning the language of the broader community. The parents of the three boys were well-educated; however, the families were facing economic hardships following their immigration due to difficulties in finding work. In the post-migration context, economic hardship has been observed in other communities of refugees (Kanu, 2008; Betancourt et al., 2015; Riggs et al., 2012). The fathers of Addir and Bakir worked and lived in another country while the family settled in Montréal. This solution resulted in the absence of a primary caregiver, an experience of many children with refugee backgrounds (Kaplan et al., 2016). In Chahid's family, his mother was able to find work quickly, but his father had still not found work, which he believed was due to his limited proficiency in French. The families also experienced shifts in roles, with mothers acting as the sole parent in the home, or as the sole income earner. In Addir's family, shifts were also observed for older siblings who acted as translators for their mother, a pattern observed in previous research (Walsh et al., 2011).

In addition to the recent changes in family contexts, families were experiencing challenges related specifically to language following their arrival in Montréal. Parents reported difficulties learning the new language, an experience reported by other communities with refugee backgrounds (Betancourt et al., 2015; Walsh et al., 2011). This limited proficiency in French created a barrier between the families and school. The parents noted that it was hard to be involved in their child's education because they had to sort through information coming from the school in the form of written memos, and they didn't understand what their child was learning at school. The impact of the language barrier on parental involvement in schooling has also been reported by parents from other communities (Walsh et al., 2011; Graham et al., 2016). Despite the importance of the home language, it is interesting to note that Chahid's father believed it was important to prioritize reading and writing in French and English, before Arabic, to ensure his child's success.

The experiences of these three refugee families are echoed in previous studies that focused on refugees from a broad range of countries (e.g., Kanu, 2008; Betancourt et al., 2015; Riggs et al., 2012; Walsh et al., 2011). The three families were experiencing a continued period of transition and 
adjustment post-migration that resulted in economic uncertainty and shifting responsibilities. In addition, they experienced important challenges in learning the language of the broader community, which impacted their communication with their school. Based on these observations, we believe that many families would benefit from extended and continued support post-migration, particularly support provided in their first language.

\section{School Contexts}

Turning to the school context, we observed school and teacher strategies to support the children's transition to school and learning of French. The children attended "welcome classes" which provide support for French language learners, but were, in this instance, centralized in a particular school, requiring some children to travel rather than attend the neighborhood school. Once children acquired sufficient proficiency in French through welcome classes, they would then be integrated into mainstream classes, and return to their neighbourhood school. While the children in our study were still in the welcome classes, this type of service organisation burdens the child and family with a second transition within just a year or two of the children starting school.

Further information about how the boys in our study were learning in school was gleaned primarily through teachers. We found the teachers to be sensitive to differences in language abilities within their classes. They were also able to recognize the consequences of limited first and second language proficiency for children, such as difficulty making friends and understanding tasks in class. However, teachers sometimes had unrealistic learning goals for the children; for example, Addir's teacher was concerned about his weak phonological awareness, a developmentally-inappropriate goal in our eyes, given that the teacher herself noted he had difficulty communicating and might be having trouble understanding what was going on in the classroom.

Despite the fact that the children were in welcome classes, where the criterion for entry is no or very little knowledge of French, the teachers reproached all three families for not being able to support French at home. At the same time, parents reported language as the main barrier to being more involved in their child's schooling. This was a troubling finding, revealing a lack of understanding on the part of teachers regarding the challenges that families with refugee backgrounds face, and the magnitude of the task of learning a new language while adapting to a new country.

In this context, we would encourage teachers to learn about each family's strengths, which in our sample included home language knowledge, valuing of education, and high levels of parental education, and to then build on these to support children's language learning. At the school level, school boards face the challenges of providing efficient services through centralized services with reducing the burden on families caused by a two-step integration into schools. Supporting families through both the initial transition and the later transition to the neighbourhood schools will be essential.

\section{Children's Language Exposure and Language Abilities}

The three boys had similar language exposure experiences with Arabic used at home and French introduced recently through school. Because their teachers believed they would benefit from additional language stimulation, these boys were recommended for the language stimulation programme. Despite these surface similarities, we were able to identify unique profiles by drawing on several sources of data. Specifically, we triangulated data from parent report of language development and bilingual language experience, from the direct assessment of the children's language in their first and second languages, and from the observation of functional communication in group settings.

Although we did not set out to provide a differential diagnosis of language disorder from limited French proficiency, the teachers referred children to the language stimulation group that they felt would benefit from additional support. The results regarding the language abilities of the three boys highlight some areas of concern. Specifically, we speculate that Addir and Bakir had delays in their first language based on the following information. First, their scores on the ALDEQ reflected multiple risk factors. When assessed directly, they both had weak receptive vocabulary in their first and second language, and weak non-word repetition (suggesting weak language processing). In the group setting, despite receiving lower scores, Addir communicated more frequently and was more outgoing, while Bakir was shy and it took considerable effort to draw him out. In contrast, Chahid had similar language exposure and some evidence of a delay in his first language, but his profile was stronger in all areas. His profile could reflect fewer risk factors (as suggested by his higher score on the ALDEQ), strengths in language processing (as measured via the non-word repetition task), and perhaps, his slightly older age at the start of the school year and subsequent placement in Grade 1. We also observed that the children responded differently to the use of Arabic in the language stimulation sessions: the use of Arabic had little impact on Addir's participation; Bakir was curious at the use of Arabic; and Chahid enjoyed using Arabic and used it to help Bakir participate. At home, Chahid's father also noted that he was often curious about translations across languages.

Overall, the results suggest that the home language is vulnerable for these children. We identified delays and weaknesses in first language development using a parent-report tool (i.e., ALDeQ) and direct assessments of the children's first language. The three boys were building on this fragile language base to acquire French as their second language. Although they are in "welcome classes" to support their learning of French, they were not receiving any additional language intervention (with the exception of participation in the language stimulation group associated with the present study). These weak language profiles may put the boys at risk for learning difficulties in school and also for lower self-esteem (Portes \& Rumbault, 2001; Wong Filmore, 2000). To foster their resiliency, it will be essential that the 
school finds a way to build bridges with the parents to support the children's language learning in both the language of school and at home.

In the absence of a gold standard for assessing multilingual children, we adopted an approach that triangulated data across measures to build rich profiles of children's language learning and language abilities. These profiles represent the children's abilities across a short time period and allowed us to build a rapport with the children and review initial impressions. For example, all three children were quite shy upon first contact, but only Bakir remained quite reserved throughout. We found that observing children across varied tasks provided a realistic picture of their language abilities, much like the observations across settings recommended by Caesar and Kohler (2007). While the profiles we obtained are not definitive for the diagnosis of a developmental language disorder, we found that they can indicate whether the child is at risk for disorder as evidenced by a weaker than expected language profile.

Throughout our study, we aimed to develop an approach that was informed by research about and experiences of people who are refugees. We incorporated the children's home language throughout by including a direct measure of Arabic vocabulary, and using Arabic in the language stimulation program, which was the context for observing functional communication. The non-word repetition task was not culturally adapted, but it is an unusual task for all young children and might thus affect performance uniformly, rather than disadvantaging only some children. Finally, the families all reported during the ALDeQ interview that book reading and shared book reading is an activity that they engaged in at home. Thus, the children were likely familiar with the kinds of interactions characteristic of the dialogic reading during which we observed their functional communication. In summary, the assessment contexts and tasks were linguistically sensitive and to the best of our knowledge, culturally sensitive. Future research, however, could explore parental perspectives on the cultural consistency of the assessment tasks and the potential impact of such tasks on their children's performance.

\section{Conclusion}

To conclude, we were able to develop rich profiles of the strengths and weaknesses of the children in this understudied population by triangulating data from multiple measures. Through these profiles, we documented what protracted language development might look like for these children. We also documented challenges in meeting the educational needs of these children for parents, struggling to support their child's learning due to very limited knowledge of the school language, and for teachers, struggling to find ways to work with families who cannot support learning in the school language at home. In alignment with Duff (2014), we found that case studies yielded important insights about the language abilities of second language learners, the environmental factors potentially influencing learning, and strategies to support language development. We also identified specific challenges faced by parents and teachers that should be explored in future research to better understand and derive solutions. We therefore recommend that future research integrate case studies even within larger group designs and plan to extend the case studies of Addir, Bakir, and Chahid as they continue participation in the language stimulation program. The focus on just a few cases was also well-suited to our aim of advancing knowledge about the language of children who have endured war and displacement while we simultaneously provided the children with immediate support to foster their language learning at home and school. 


\section{References}

American Speech-Language-Hearing Association (n.d.). Bilingual Service Delivery (Practice Portal). Retrieved December 30, 2019, from https://www.asha.org/PracticePortal/Professional-Issues/Bilingual-ServiceDelivery

Al Janaideh, R. (2019). Arabic Vocabulary Subtest.

Bedore, L. M., \& Pena, E. D. (2008). Assessment of bilingual children for identification of language impairment: Current findings and implications for practice. International Journal of Bilingual Education and Bilingualism, 11(1), 1-29. doi.org/10.2167\%2Fbeb392.0

Betancourt, T. S., Abdi, S., Ito, B. S., Lilienthal, G. M., Agalab, N., \& Ellis, H. (2015). We left one war and came to another: Resource loss, acculturative stress, and caregiver-child relationships in Somali refugee families. Cultural Diversity and Ethnic Minority Psychology, 2l(1), 114-125. doi:10.1037/a0037538

Bunce, B. H. (2008). Early literacy in action: The language-focused curriculum for preschool. Baltimore, MD: Paul H. Brookes.

Caesar, L. G., \& Kohler, P. D. (2007). The state of schoolbased bilingual assessment: Actual practice versus recommended guidelines. Language, Speech, and Hearing Services in Schools, 38(3), 190-200. doi:10.1044/0161-1461(2007/020)

Comité de la gestion de la taxe scolaire de l'Ile de Montréal (2018). Portrait socioculturel des élèves inscrits dans les écoles publiques de l'île de Montréal. Retrieved April 9, 2019 from https://www.cgtsim.qc.ca/en/documents-siteweb/380-portrait-socioculturel-inscription-20182019/file

Courcy (2000). Conscience phonologique et apprentissage de la lecture. Unpublished doctoral dissertation. Montréal: Université de Montréal.

DeFeyter, J. J., \& Winsler, A. (2009). The early developmental competencies and school readiness of low-income, immigrant children: Influences of generation, race/ethnicity, and national origins. Early Childhood Research Quarterly, 24(4), 411-431. doi: 10.1016/j.ecresq.2009.07.004

Dollaghan, C. A, \& Horner, E. A. (2011). Bilingual language assessment: A meta-analysis of diagnostic accuracy. Journal of Speech, Language, and Hearing Research, 54(4), 1077-1088. doi:10.1044/1092-4388(2010/10-0093)

Duff, P.A. (2014). Case study research on language learning and use. Annual Review of Applied Linguistics, 34, 1-23. doi:10.1017/S0267190514000051

Duff, P. A. \& Anderson, T. (2015). Case-study research. In
J. Dean Brown \& C. Coombe (Eds.) The Cambridge guide to research in language teaching and learning (pp. 112-118). Cambridge, UK: Cambridge University Press.

Dunn, L., Thériault-Whalen, C. M., \& Dunn, L. (1993). Échelle de vocabulaire en images Peabody. Adaptation française du Peabody Picture Vocabulary Test. Toronto, ON: Psycan.

Gathercole, S. (2006). Non-word repetition and word learning: The nature of the relationship. Applied Psycholinguistics, 27(4), 513-543. doi:10.1017/S0142716406060383

Gillam, R. B., Peña, E. D., \& Miller, L. (1999). Dynamic assessment of narrative and expository discourse. Topics in Language Disorders, 20(1), 33-47. doi:10.1097\%2F00011363-19991100000005

Graham, H. R., Minhas, R. S., \& Paxton, G. (2016). Learning problems in children of refugee background: A systematic review. Pediatrics, 137(6), 1-15. doi:10.1542/peds.2015-3994.

Houle, R. (2019). Results from the 2016 Census: Syrian refugees who resettled in Canada in 2015 and 2016. Insights on Canadian Society. February Statistics Canada Catalogue no. 75-006-X.

Huennekens, M. E., \& Xu, Y. (2016). Using dialogic reading to enhance emergent literacy skills of young dual language learners. Early Child Development and Care, 186, 324-340. doi:10.1080/03004430.2015.1031125

Kanu, Y. (2008). Educational needs and barriers for African refugee students in Manitoba. Canadian Journal of Education, 31(4), 915-940.

Kaplan, I., Stolk, Y., Valibhoy, M., Tucker, A., \& Baker, J. (2016). Cognitive assessment of refugee children: Effects of trauma and new language acquisition. Transcultural Psychology, 53(1), 81-109. doi:10.1177/1363461515612933

MacLeod, A. A. N, Meziane, R. S., \& Pesco, D. (In Press). Developing StimuLER: Supporting the home and school languages of children arriving as refugees. Canadian Diversity.

McBrien, J. L. (2005). Educational needs and barriers for refugee students in the United States: A review of the literature. Review of Educational Research, 75(3), 329-364. doi:10.3102/00346543075003329

Ministère de l'Éducation, du Loisir, et du Sport. (2014). Cadre de référence. Accueil et intégration des élèves issus de l'immigration au Québec: Organisation des services. Retrieved from Accueillntegration_2_OrganisationServices.pdf

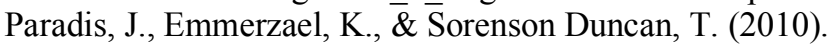 Assessment of English language learners: Using parent report on first language development. Journal of Communication Disorders, 43, 474497. doi:10.1016/j.jcomdis.2010.01.002

Portes, A., \& Rumbaut, R. G. (2001). Legacies: The story 
of the immigrant second generation. Oakland, CA: University of California Press.

Québec. Loi sur l'instruction publique, I-13.3, r. 210, updated to 1 december 2019 [Québec], Éditeur officiel du Québec, (C2019.

Riggs, E., Davis, E., Gibbs, L., Block, K., Szwarc, J., Casey, S., ... \& Waters, E. (2012). Accessing maternal and child health services in Melbourne, Australia: Reflections from refugee families and service providers. BMC Health Services Research, 12(1), 1-16. Retrieved from https://bmchealthservres.biomedcentral.com/track/ pdf/10.1186/1472-6963-12-117

Shakya, Y. B., Guruge, S., Hynie, M., Akbari, A., Malik, M., Htoo, S., ... \& Alley, S. (2012). Aspirations for higher education among newcomer refugee youth in Toronto: Expectations, challenges, and strategies. Refuge: Canada's Journal on Refugees, 27(2), 65-78.

Sinclair, M. (2001). Education in emergencies. In J. Crisp, C. Talbot, \& D. B. Cipollone (Eds.) Learning for a future: Refugee education in developing countries (pp. 1-84). Geneva, Switzerland: United Nations Publications.

Sirin, S. R., \& Rogers-Sirin, L. (2015). The educational and mental health needs of Syrian refugee children. Washington, DC: Migration Policy Institute. Retrieved from https://www.migrationpolicy.org/research/educatio nal-and-mental-health-needs-syrian-refugeechildren

Strekalova, E., \& Hoot, J. L. (2008). What is special about special needs of refugee children? Guidelines for teachers. Multicultural Education, 16(1), 21-24.

Sullivan, A. L., \& Simonson, G. R. (2016). A systematic review of school-based social-emotional interventions for refugee and war-traumatized youth. Review of Educational Research, 86(2), 503-530. doi:10.3102/0034654315609419

Thordardottir, E., Kehayia, E., Mazer, B., Lessard, N., Majnemer, A., Sutton, A., ... \& Chilingaryan, G. (2011). Sensitivity and specificity of French language and processing measures for the identification of primary language impairment at age 5. Journal of Speech, Language, and Hearing Research, 54(2), 580-597. doi:10.1044/10924388(2010/09-0196)

Topping, K., Dekhinet, R., \& Zeedyk, S. (2013). Parentinfant interaction and children's language development. Educational Psychology, 33(4), 391426. doi:10.1080/01443410.2012.744159

Tsybina, I., \& Eriks-Brophy, A. (2010). Bilingual dialogic book-reading intervention for preschoolers with slow expressive vocabulary development. Journal of Communication Disorders, 43, 538-556. doi:10.1016/j.jcomdis.2010.05.006

Ungar, M. (2008). Resilience across cultures. The British
Journal of Social Work, 38(2), 218-235. doi:10.1093/bjsw/bcl343

Unicef Canada (2019). Syrian refugees. Retrieved from https://www.unicef.org/appeals /syrianrefugees.html

United Nations High Commissioner for Refugees (2000). The UNHCR global report 1999. New York, NY: Oxford University Press.

United Nations Security Council (2015). 7592nd Meeting. Briefing on the humanitarian situation in Syria. Remarks by António Guterres, United Nations High Commissioner for Refugees. Retrieved from http://www.unhcr.org/admin/hcspeeches/56786145 9/united-nations-security-council-7592nd-meetingbriefing-humanitarian-situation.html

van Ijzendoorn, M. H., Dijkstra, J., \& Bus, A. G. (1995). Attachment, intelligence, and language: A metaanalysis. Social Development, 4(2), 115-128. doi:10.1111/j.1467-9507.1995.tb00055.x

Walsh, C. A., Este, D., Krieg, B., \& Giurgiu, B. (2011). Needs of refugee children in Canada: What can Roma refugee families tell us? Journal of Comparative Family Studies, 42(4), 599-613. doi: $10.3138 /$ jcfs.42.4.599

Wilkinson, L. (2002) Factors influencing the academic success of refugee youth in Canada. Journal of Youth Studies, 5(2), 173-193. doi:10.1080/13676260220134430

Wong Fillmore, L. (2000). Loss of family languages: Should educators be concerned? Theory into Practice, 39, 203-210. doi:10.1207/s15430421tip3904_3.

Zevenbergen, A. A., \& Whitehurst, G. J. (2003). Dialogic reading: A shared picture book reading intervention for preschoolers. In A. van Kleeck, S. A. Stahl, \& E. B. Bauer (Eds.), On reading books to children: Parents and teachers (pp. 177-200). Mahwah, New Jersey: Lawrence Erlbaum. 
